\title{
Comparison between the Immediate Effects of Instrument Assisted Soft Tissue Mobilization and Active Release Technique in Individuals Wearing High Heels
}

\author{
Jahnvi T. Shah ${ }^{1}$, Mayuri Ghumatkar ${ }^{2}$, Ajay Kumar ${ }^{3}$ \\ 'B.P.Th, DPO's NETT College of Physiotherapy, Thane, Maharashtra, India. \\ ${ }^{2}$ M.P.Th, Associate Professor, DPO's NETT College of Physiotherapy, Thane \\ ${ }^{3}$ M.P.Th, Principal, DPO's NETT College of Physiotherapy, Thane.
}

Corresponding Author: Jahnvi T. Shah

\begin{abstract}
Background: Wearing high heels regularly places muscle-tendon units (MTUs) in a shortened position. In this condition the length of the calf MTU (gastrocnemius-soleus) is reduced by the continuous ankle plantar flexion cause by the heel lift imposed by the high heels, which leads to concomitant inflexibility of these muscles. Tightness of these muscles in turns leads to formation of trigger points within the muscles. Instrument-assisted soft tissue mobilization (IASTM) is an approach to soft tissue manipulation that uses concave and convex stainless steel instruments to release scar tissue, break soft tissue adhesions, and remove fascial restrictions. Active Release Techniques, or ART, is a soft tissue treatment method that focuses on relieving tissue tension via the removal of fibrosis/adhesion that develops in tissue that is overloaded with repetitive use.

Objective: To compare the immediate effect of Instrument Assisted Soft Tissue Mobilization and Active Release Technique for gastrosoleus muscle in individuals wearing high heels using VAS and active dorsiflexion using universal goniometer.

Method: 30 subjects were selected as per inclusion and exclusion criteria and were randomly allocated into two groups of 15 each. Group A received Instrument Assisted soft tissue mobilization and Group B received Active Release Technique for Gastro-soleus muscle. Pre and Post intervention Dorsiflexion range of motion and VAS scores were analysed.

Result: The statistical analyses showed that there is signification increase in dorsiflexion range of motion and significant reduction in pain in both the groups. $(\mathrm{p}<0.0001)$. However, inter group analysis showed that Group A is much more effective in improving the range of motion and reducing pain scores.

Conclusion: The present study concluded that Instrument Assisted Soft Tissue Mobilization is a better intervention for the release of trigger points as it shows greater increase in ankle dorsiflexion range of motion and a significant pain reduction when compared to Active Release Technique.
\end{abstract}

Keywords: Instrument Assisted Soft Tissue Mobilization(IASTM), Active Release Technique(ART), Range of Motion, pain, High Heels, Calf Muscles.

\section{INTRODUCTION}

Skeletal muscle is a highly malleable tissue that can adapt both morphologically and functionally to chronic alterations in mechanical loading ${ }^{1}$. Over exertion of these skeletal muscles and poor posturing leads to soft tissue injuries. 
In human s, one common condition that places muscle-tendon units (MTUs) in a shortened position is high heel wearing. In this condition the length of the calf MTU (gastrocnemiussoleus) is reduced by the continuous ankle plantar flexion cause by the heel lift imposed by the high heels ${ }^{1}$.Thus regular wearing of high heels would lead to shortening of the fascicles of the gastrocnemius muscle together with changes in the mechanical properties of the Achilles' Tendon, resulting in functional alteration. ${ }^{1}$

\section{ANATOMY OF FASCIA:}

Superficial fascia also known as Subcutaneous Tissue is an enveloping layer of dense, areolar connective tissue and fats. ${ }^{2}$

The Subcutaneous tissue connects the skin to the underlying dense deep fascia which invests muscle and aponeurosis throughout the body. ${ }^{2}$

Superficial fascia provides a protective cushion for the musculoskeletal framework over which they slide. Sheets of collagen fibres coupled with elastin facilitate this mobility. The space between the collagen sheets facilitate sliding, while stretching results in realignment of collagen fibres within shape. $^{2}$

\section{ROLE OF FASCIA:}

Support and protection.

Proprioception

Mobility

Lubrication

Shape

Fat storage

Repair/ healing

Defense

Shock absorption ${ }^{2}$

DYSFUNCTION

\section{FASCIA:}

Restrictive scar tissue

Localized trigger points
Weakness and increased tone

Adaptive muscle shortening

Injury to musculo-tendinous structres. ${ }^{2}$

Studies conducted showed the effectiveness of various techniques such as instrument assisted soft tissue mobilization, active release technique, self-myofascial release, etc joint range of motion, reduce fascia/muscle tightness, and muscle activation. ${ }^{3,4}$

\section{INSTRUMENT ASSISTED SOFT} TISSUE MOBILIZATION (IASTM).

Instrument-assisted soft tissue mobilization (IASTM) is an approach to soft tissue manipulation that uses concave and convex stainless steel instruments to release scar tissue, break soft tissue adhesions, and remove fascial restrictions. $^{7}$

\section{ACTIVE RELEASE TECHNIQUE (ART)}

Active Release Techniques, or ART, is a soft tissue treatment method that focuses

on relieving tissue tension via the removal of fibrosis/adhesion that develops in tissue that is overloaded with repetitive use. ${ }^{4}$

\section{MATERIALS AND METHODOLOGY}

The study was a comparative study where 30 women wearing high heels were selected using random sampling. Inclusion Criteria: Individuals wearing high heels who are willing to participate. Ankle Dorsiflexion ROM: reduced. Pain scale showing more than 3. Duration of Wearing heels: minimum 1 year. Wearing heels for minimum 5 times a week and 5 hours a day. Heel height: 2" and above. Exclusion Citeria: Musculoskeletal injury or surgery of lower limb. Acute Cardio-Respiratory or Neurological condition. Medical or surgical co-morbidities. Materials used in the study included universal half circle goniometer, IASTM tool, plinth, paper and pen. 


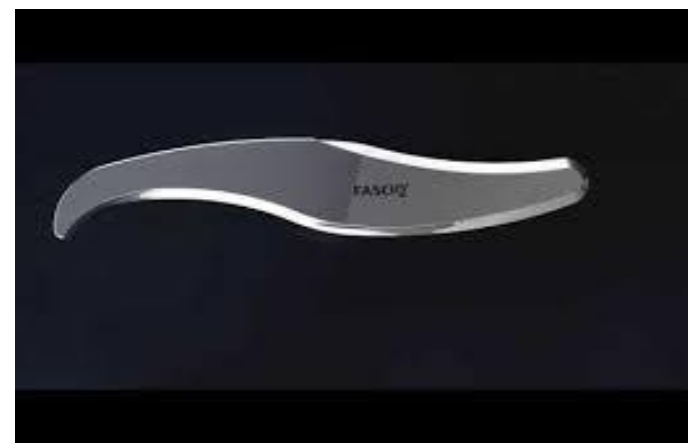

IASTM TOOL

PROCEDURE:

30 individuals who are willing to participate was included in the study.

Written informed consent was taken from all the individuals.

All subjects were screened as per inclusion and exclusion criteria by taking detailed pain history and assessment.

Purpose of the study and the procedure was explained to the subjects prior to the study in their respective language.

The subjects were then dividsed into two groups: Group A ( 30 subjects) and Group B ( 30 subjects).

Ankle dorsiflexion range of motion was assessed using universal half goniometer for subjects of both the groups.

Pain was assessed using Visual analogue scale.

Instrument assisted soft tissue mobilization was performed on the subjects of group A and Active Release Technique was performed on the subjects of group B.

\section{TECHNIQUE:}

Instrument assisted soft tissue mobilization: Patient position: Prone with feet outside the plinth.

Therapist position: At the edge of plinth.

\section{Technique:}

First apply a cream or moisturizer to the part affected.

Then give gentle strokes from proximal to distal to check for trigger point or taut band

After knowing the exact location, give gentle strokes with minimal pressure in

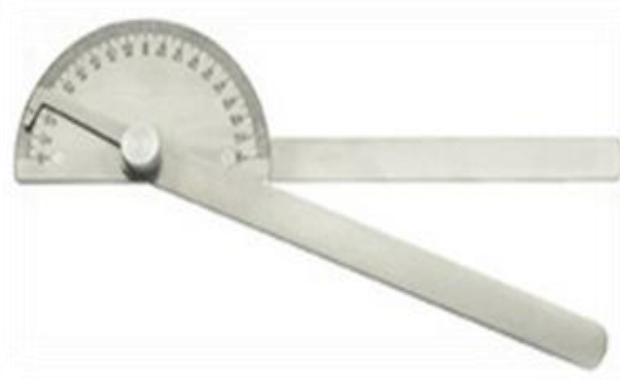

\section{GONIOMETER}

all directions by keeping the instrument in 30 to 60 degree angle.

Application time should be between 40120 seconds.

Active release technique

Patient position: Prone with feet outside the plinth.

Therapist position: At the edge of plinth.

\section{Technique:}

Palpate the patients calf region and find a trigger point or tender point. Apply Pressure Manually over the point and lengthened the muscle or ask the patient to actively lengthen the muscle from shortened position.

Movement should be repeated 15 times.

Post the treatment immediate effect on pain and ankle ROM of both the techniques was re-assesed.

The data was collected and was appropriately statistically analysed to compare the difference between immediate effect of Instrument assisted soft tissue mobilization and Active Release technique on ankle dorsiflexion ROM.

\section{Active release technique}

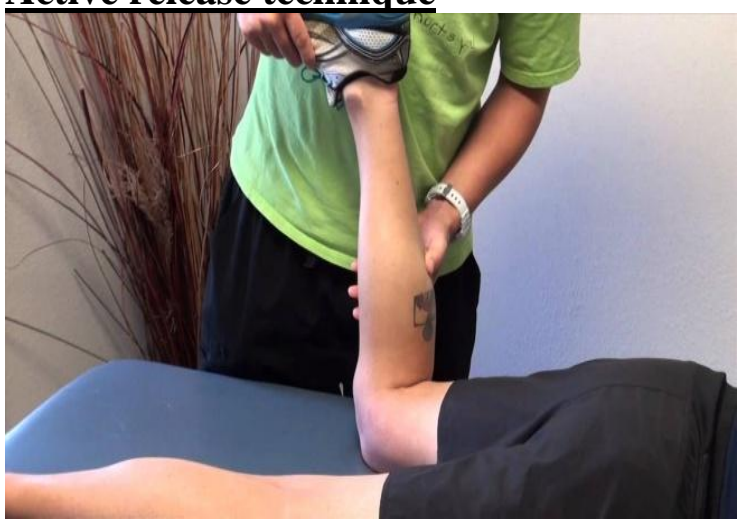




\section{Instrument assisted soft tissue} mobilization.

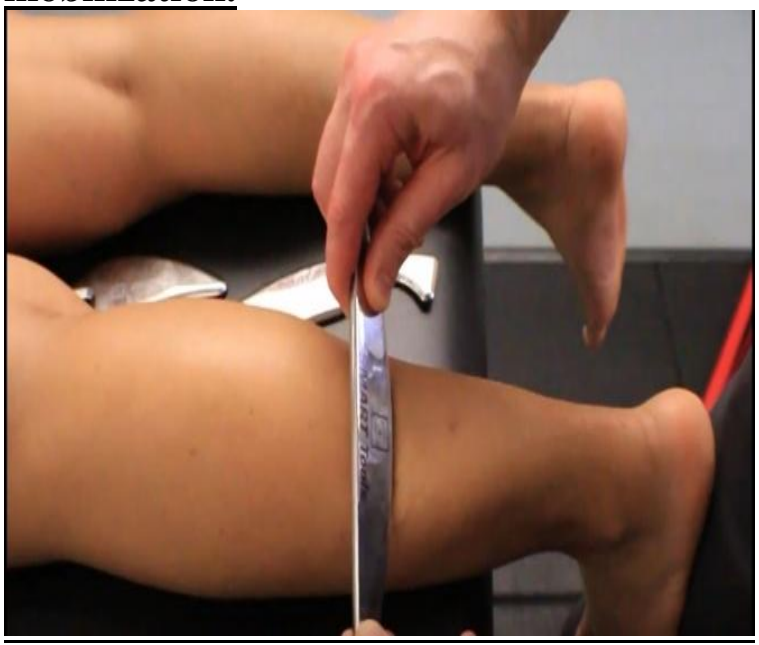

\section{STATISTICAL ANALYSIS:}

Collected data was entered in Microsoft Excel and Graph Pad Prism 9.2.1 was used for Data Analysis. Normality of the data of range of motion and pain scores for both the groups was tested using Shapiro-Wilk test. Since most of the data was not normally distributed for both range of motion and pain scores for both the groups on both the limbs, statistical analysis was done using non-parametric tests, i.e for within group comparison was done using Wilcoxon signed Rank test and inter group comparison was done using the MannWhitney $U$ test for both the groups. Since one group passed the normality test, statistical analysis was done using parametric tests, i.e. within group was done using paired ' $\mathrm{t}$ ' test.

\section{RESULTS}

The result of Mann Whitney U test for inter-group comparison shows that Instrument Assisted Soft Tissue Mobilization is statistically more significant in improving the pain and range of motion scores when compared to Active Release Technique $(\mathrm{P}<0.0001)$.

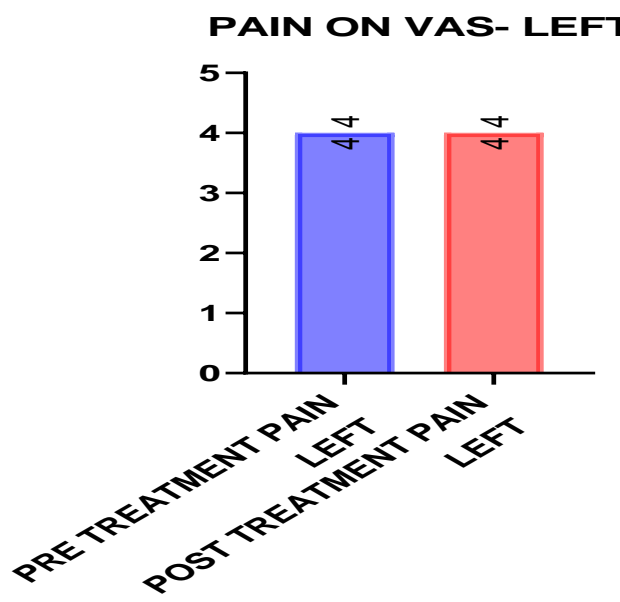

Inference-

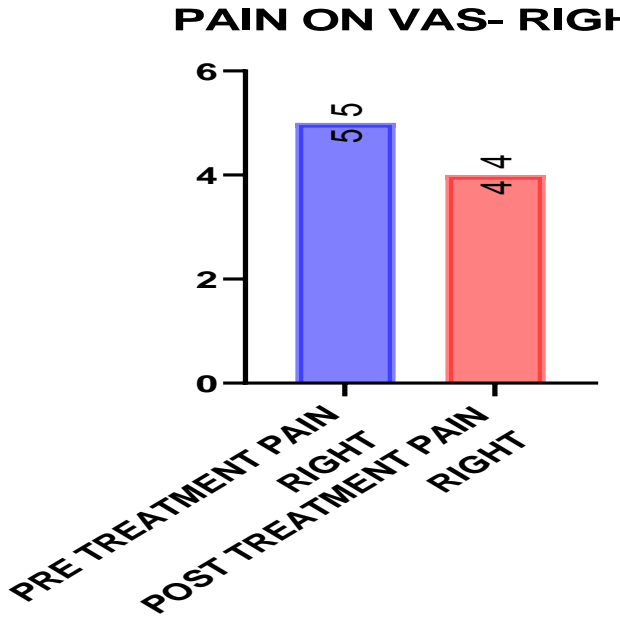

Graph 1 and 2-comparison of pre and post pain scores following ART (rt and lt)

The above data did not pass the normality Test, hence Wilcoxon Signed rank test was used. The above graph showed a significant reduction in Pain scores on RTside following the application of ART $(\mathrm{p}<0.0001)$
The above data did not pass the normality test, hence Wilcoxon Signed rank test was used. The above graph shows that there was no significant reduction in Pain scores on LT side following application of ART $(\mathrm{p}<0.0001)$ 
Jahnvi T. Shah et.al. Comparison between the immediate effect of instrument assisted soft tissue mobilization and active release technique in individuals wearing high heels.

ROM-RIGHT

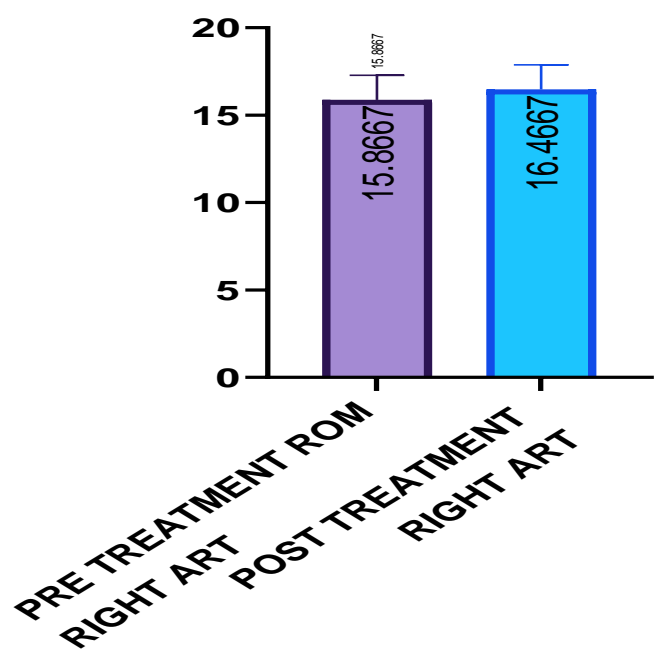

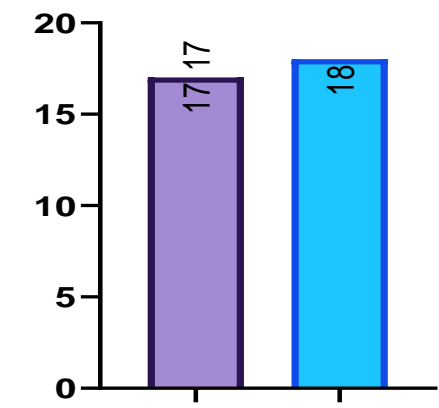

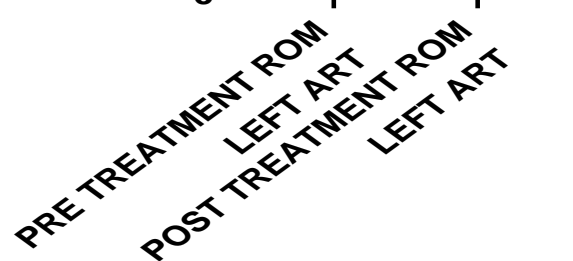

Graph 3 and 4- comparison of pre and post ankle dorsiflexion ROM following ART

\section{Inference}

The above data passed the normality test, Hence paired t-test was used. The above graph shows that there was significant increase in ankle dorsiflexion range on RT side following the application of ART $(\mathrm{p}<0.0001)$

\section{PAIN ON VAS-RT}

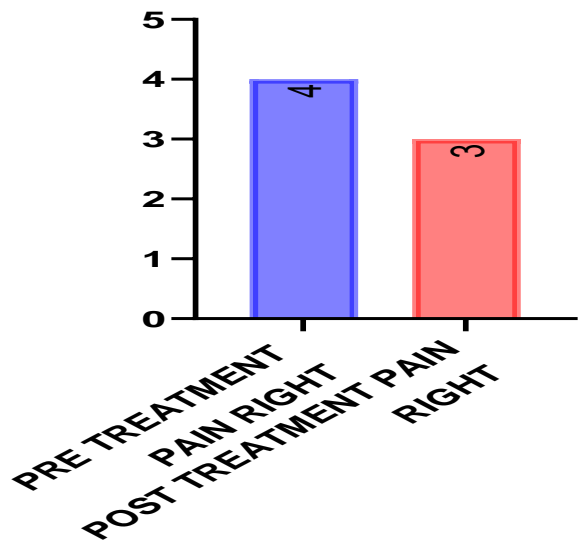

The above data did not pass the normality test, hence Wilcoxon Signed rank test was used. The above graph shows that there was significant increase in ankle dorsiflexion range on LT side following the application of ART $(\mathrm{P}<0.0001)$

\section{Graph 5 and 6- comparison of pre and post pain scores following IASTM ( rt and lt)}

The above data did not pass the normality test, hence Wilcoxon Signed rank test was used. The above graph shows that there was Significant reduction in Pain scores on RT side following the application of IASTM $(\mathrm{p}<0.0001)$
PAIN ON VAS- LEFT

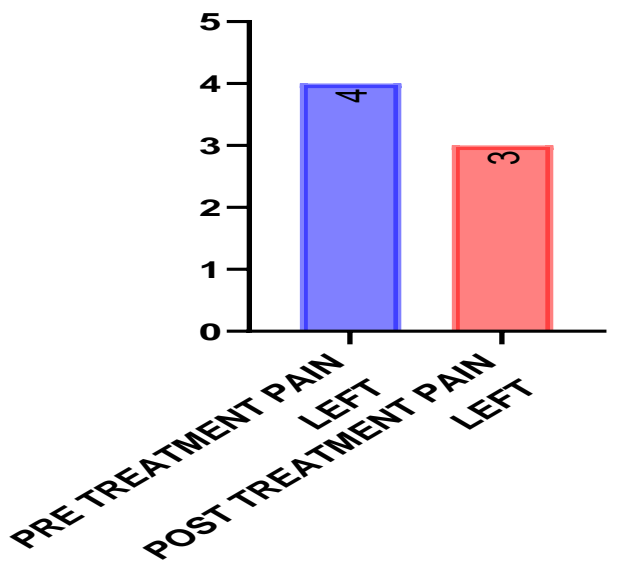

The above data did not pass the normality test, hence Wilcoxon Signed rank test was used. The above graph shows that there was significant reduction in Pain scores on LT side following application of IASTM $(\mathrm{p}<0.0001)$ 
Jahnvi T. Shah et.al. Comparison between the immediate effect of instrument assisted soft tissue mobilization and active release technique in individuals wearing high heels.

ROM-RIGHT

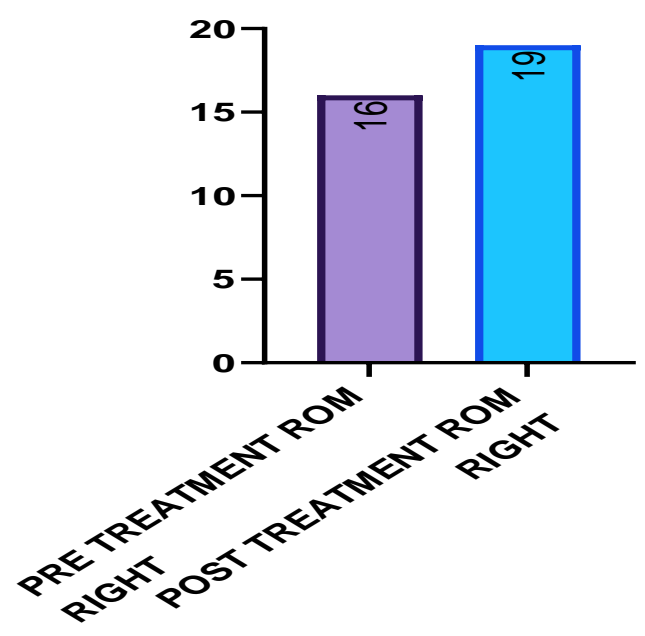

ROM-LEFT

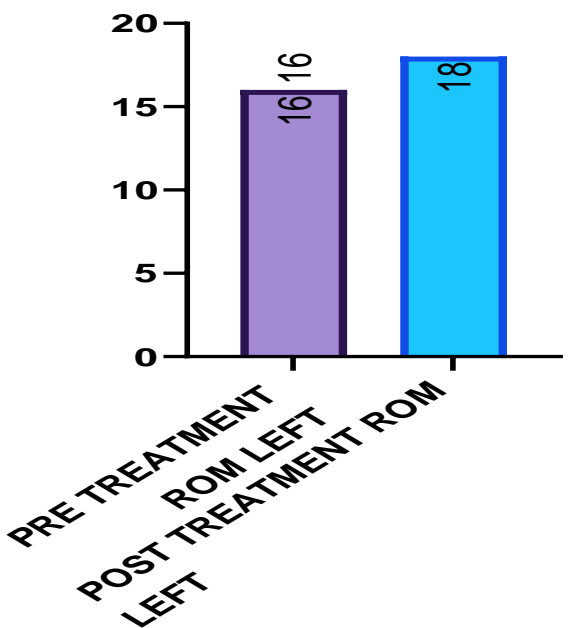

Graph 7and 8- comparison of pre and post ankle dorsiflexion ROM following IASTM ( rt and lt)

\section{Inference}

The above data did not pass the normality test,hence Wilcoxon Signed rank test was used.The above graph shows that there was significant increase in ankle dorsiflexion range on $\mathrm{RT}$ side following the application IASTM $(\mathrm{p}<0.0001)$.

\section{DIFFERENCE IN PAIN- RIGHT}

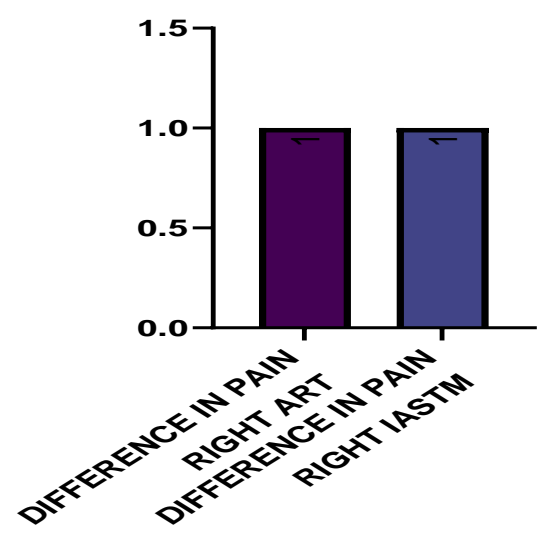

The above data did not pass the normality test, hence Wilcoxon Signed rank test was used. The above graph shows that there was significant increase in ankle dorsiflexion range on LT side following the application of IASTM ( $<<0.0001)$.

\section{Inference}

Graph 9 and 10- comparison of pain scores following IASTM and ART ( rt and lt)

The above data did not pass the normality

Test, hence Mann-Whitney U test was used. The above graph shows that when both the groups were compared on RT side there was a significant difference in both groups $(\mathrm{p}<0.05)$

\section{DIFFERENCE IN PAIN- LEFT}

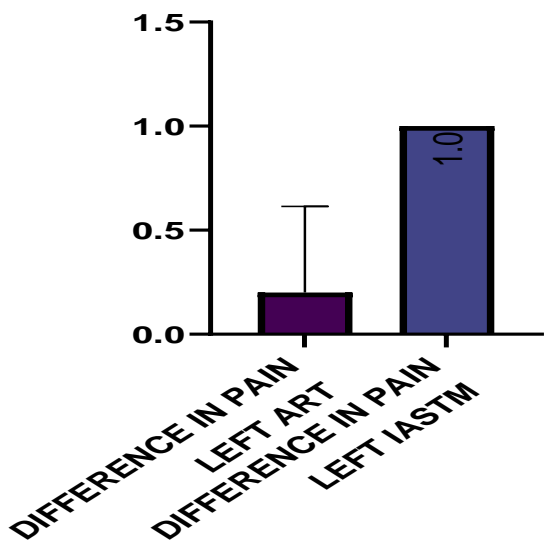

The above data did not pass the normality Test, hence Mann-Whitney U test was used. The above graph shows that when both the groups were compared group B(IASTM) showed significant difference in reduction in Pain than group A(ART) $\mathrm{p}(<0.05)$ 
DIFFERENCE IN ROM- RIGHT

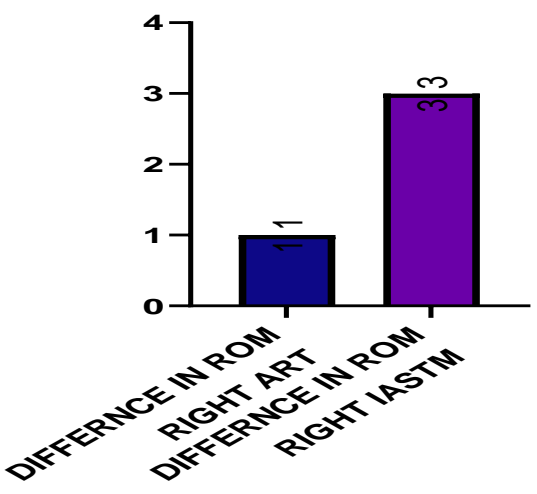

DIFFERENCE IN ROM- LEFT

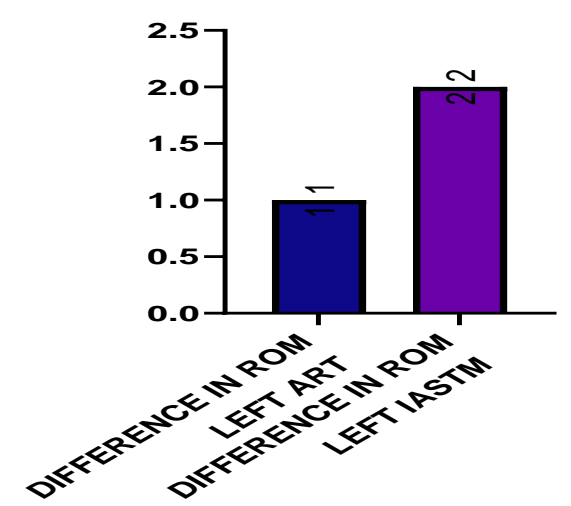

Graph 11 and 12- Comparsion range of motion following IASTM and ART( rt and It)

Inference

The above data did not pass the normality

Test, hence Mann-Whitney U test was used.

The above graph shows that when both

the groups were compared on RT side,

group B(IASTM) showed a greater increase

in the ankle dorsiflexion range of motion

than group A ( ART) with p value $<0.0001$

\section{DISCUSSION}

The aim of the study was to compare the immediate effect of Instrument Assisted Soft Tissue Mobilization and Active Release Technique on individuals wearing high heels. The sample consisted of 30 samples. They were divided into 2 groups, each containing 15 subjects. VAS was used to assess pain and goniometer was used to assess ankle dorsiflexion range of motion. The data was collected and analysed using non-parametric tests (Wilcoxon and Mann-Whitney test)

Graph 1 and 2 shows there is significant reduction in pre(median-5) and post (median- 4) on right and pre(median-4) and post (median-4) on left pain scores on VAS after the application of Active Release technique. This finding is supported by the study of Jun ho kim. et al, where active release technique significantly decreased pain scores in patients with chronic neck pain.

Graph 3 and 4 shows there is significant increase in the pre(Mean15.8667) and post(mean-16.4667) on right side and pre(median -17) and post
The above data did not pass the normality Test, hence Mann-Whitney U test was used. The above graph shows that when both the groups were compared on left side, group B (IASTM) showed greater increase in the ankle dorsiflexion range of motion than group A ( ART) with p value $<0.0001$.

(median-18) on left side dorsiflexion range of motion after the application of Active Release Technique $(p<0.0001)$. This finding was supported by the study of James W. et al, where active release technique showed immediate effect on restricted ankle dorsiflexion range of motion, thus improving the flexibility of hamstring muscle.

Graph 5 and 6 shows there is significant decrease in pre( median-4) and post (median-3) on right side and pre(median-4) and post (median-3) on left side pain scores on VAS after application of Instrument Assisted Soft Tissue Mobilization. This finding is supported by the study of Jooyoung kim ,et. Al. where Instrument assissted soft tissue mobilization showed significant reduction in pain scores $(\mathrm{p}<0.0001)$

Graph 7 and 8 shows there is significant increase in pre(median-16) and post (median-19) on right side and pre(median-16) and post (median-18) on left side ankle dorsiflexion range of motion after the application of instrument assisted soft tissue mobilization. This result was suuported by 
the study of Ikeda $\mathrm{N}$, et. Al, where immediate effect of instrument assisted soft tissue mobilization showed significant increase in dorsiflexion range of motion.

According to the interpretation of data in graphs 9 and 10, both the groups when compared, there was significant difference observed in both the groups with Group B (IASTM) showing reduction in pain when compared to Group A (ART) $(\mathrm{P}<0.0001)$ on both the limbs. IASTM is a skilled intervention that includes the use of specialized tools to manipulate the skin, myofascia, muscles, and tendons by various direct compressive stroke techniques. IASTM have stimulated the A-beta sensory fibers to block the Adelta and C-fibers. As per the pain gate control theory of pain management, as long as the sensory fibers are firing, the gate to the transmission of pain is closed. This blocks the substance $\mathrm{P}$ from the pain receptors via presynaptic inhibition at the dorsal horn ${ }^{8}$. IASTM have a neurophysiological effect as it stimulates mechanosensitive neurons through skin deformation by the instrument. Mechanosensitive neurons include mechanoreceptors which are responsible for two-point discrimination and mechano-nociceptors which are responsible for pain perception. IASTM changed the neural activity of the large mechanoreceptor neurons affecting the two-point discrimination. This improves local tactile sense through mechanoreceptors stimulation and a decrease in the pain pressure threshold which suggest that light IASTM modulated the nociceptors (small pain fibres) activity. This study was conducted by Dawn T. Gulick, et al, on instrument assisted soft tissue mobilization increases myofascial trigger point pain threshold also a study was conducted by Weiqing Ge et al, on effect of instrument assisted soft tissue mobilization on mechanosensitive neurons 9 .
According to the interpretation of data in graphs 11 and 12, both the groups when compared, group $\mathrm{B}$ i.e. Instrument Assisted Soft Tissue Mobilization shows greater increase in the ankle dorsiflexion range of motion on both the sides than group $\mathrm{A}$ i.e. Active Release Technique. The biggest goal of IASTM is to remove scar tissues and promote a return to normal function following soft tissue regeneration. Microvascular and capillary hemorrhage, along with localized inflammation, can occur as a result of using IASTM to apply appropriate pressure and shear force to the soft tissue. Such inflammation restarts the healing process by removing the scar tissue and releasing adhesions, while also increasing blood and nutrient supply to the injured area and migration of fibroblasts. IASTM improves the extensibility of soft tissues by treating their restrictions and when heat is generated from friction by the instrument, the viscosity of the tissue decreases, making it softer. Physiologically, a decrease in the viscosity of tissue improves ROM. When mechanical stress is exerted on the muscle fascia, intrafascial mechanoreceptors become stimulated. This change alters the proprioceptive input sent to the central nervous system, which in turn changes the tension in tissue-related motor units ${ }^{6}$. This study was conducted by Jooyoung Kim et al, on therapeutic effectiveness of instrument assisted soft tissue mobilization for soft tissue injury: mechanisms and practical application ${ }^{6}$.

On basis of statistical reference, the present study supports the previous studies that both Active Release Technique and Instrument Assisted Soft Tissue Mobilization show a significant increase in ankle dorsiflexion range of motion as well as reduction in pain after the release of the gastrocnemius trigger points.

However, the current study aimed at the comparison of immediate effect of 
Instrument assisted soft tissue mobilization and Active Release Technique on pain as well as dorsiflexion range of motion. The inter-group analysis concluded that Instrument Assisted Soft Tissue Mobilization is much more effective for improving range of motion and pain scores when compared to Active Release Technique and hence it can be applied in clinical practice.

The main limitation of the study was that it was performed on a small sample size and only the immediate effect on range of motion and pain was taken into consideration rather than the long term effect. Further studies can take into consideration the long term effect of IASTM and ART on trigger points and also consider various age groups involved in other similar profession.

\section{CONCLUSION}

The present study concluded that Instrument Assisted Soft Tissue Mobilization is a better intervention for the release of trigger points as it shows greater increase in ankle dorsiflexion range of motion and a significant pain reduction when compared to Active Release Technique.

\section{Clinical Implication:}

Trigger points and taut bands in the calf muscles can be released using Instrument Assisted Soft Tissue Mobilization so that women wearing high heels regularly can work pain free and more efficiently.

Instrument assisted soft tissue mobilization can be applied on other myofascial trigger points as well which lead to pain and restricted movements.

\section{Abbreviations}

MTU-Musculo-tendinous unit

IASTM- Instrument Assisted Soft Tissue Mobilization

ART- Active Release Technique

ROM- Range of Motion
VAS- Visual Analogue Scale

\section{ACKNOWLEDGEMENTS}

I express my deep sense of gratitude and sincere thanks to our respected sir Dr. Ajay Kumar and guide Dr. Mayuri Ghumatkar who immensely helped me with the sincere guidance, untiring cooperation, valuable advice and endless inspiration during the course of the study. I also take this opportunity to thank my family members and friends for their help and support.

\section{Conflict of Interest: None}

\section{Source of Funding: None}

\section{Ethical Approval: Approved}

\section{REFERENCES}

1. R. Caspo , C.N. Maganaris, O.R. Seynnes, M.V. Narici. On Muscle,Tendon and High Heels. Journal of Experimental Biology 2010 213:2582-2588. DOI:10.1242/jeb.044271.

2. Robert Schleip, Heike Jager and Warner Klingler. Fascia is alive.157-164. 10.1016/B978-0-7020-3425-1.00057-X.

3. Ikeda N, Otsuka S, Kawanishi Y, Kawakami Y. Effects of Instrument Assisted Soft tissue Mobilization On Musculoskeletal Properties. Medicine and Science in Sports and Exercise. 2019, 51(10) 2166-2172. DOI:10.1249/MSS.0000000000002035

4. Andreo A. Spina, BKin , DC*. External Coxa saltans(snapping hip) treated with Active release technique: a case report. The journal of Canadian Chiropractic Association. 2007,Mar.51(1):23-29.

5. James. W George, Andrew C. Tunstall, Rodger E. Tepe PhD, Clayton D. Skaggs. The effects of active release technique on hamstring flexibility :pilot study. the journal of manipulative and physiological therapeutics. Volume 29, issue 3 Mar-April 2006, pg 224-227 DOI:10.1016/j.jmpt.2006.01.008.

6. Jooyoung kim, Dong Jun Sung and Jooyoung Lee. Therapeutic effectiveness of instrument assisted soft tissue mobilization for soft tissue injury: mechanisms and 
Jahnvi T. Shah et.al. Comparison between the immediate effect of instrument assisted soft tissue mobilization and active release technique in individuals wearing high heels.

practical application. Journal of exercise rehabilitation. 2017 Feb; 13(1),12-22. DOI:10.12965/jer.1732824.412

7. James R. Scifers, DScPT, PT, SCS, LAT, ATC; Russell Baker, DAT, ATC; Alison Gardiner-Shires, PhD, LAT, ATC; Phillip Vardiman, PhD, LAT, ATC. Instrument assisted soft tissue mobilization. Athletic training and sports health care. 2017;9(2):49-52. DOI:10.3928/1942586420170223-001.

8. Weiqing Ge, DPT, PhD, Emily Roth, SPT, and Alyssa Sansone, SPT. A quasiexperimental study on the effects of instrument assisted soft tissue mobilization on mechanosensitive neurons. Journal of physical therapy Science. 2017 Apr; 29(4): 654-657. DOI: 10.1589/jpts.29.654

9. Dawn T.Gulick. Instrument Assisted Soft Tisuue Mobilization increases myofascial trigger point pain threshold. Journal of Bodywork and Movement Therapies. April 2018. DOI;10.1016/j.jbmt.2017.10.012

10. James W.Youdas, Connie L.Bogard, Vera J.Suman. Reliability of goniometric measurements and visual estimates of ankle joint active range of motion obtained in a clinical setting. Archives of Physical Medicine and Rehabilitation. October 1993.DOI.org/10.1016/00039993(93)90071-H

11. Russell T. Baker, DAT, ATC; Alan Nasypany, EdD, ATC, LAT; Jeff G. Seegmiller, EdD, ATC, LAT. Instrumentassissted soft tissue mobilization treatment for tissue extensibility dysfunction.
International journal of Athletic Therapy and Training.September 2013.

12. Kevin Laudner, Bryce D. Compton, Todd A. McLoda, and Chris M. Walters. Acute effects of Instrument Assisted Soft Tissue Mobilization for improving posterior glide range of motion in collegiate baseball players. International journal of sports physical therapy. Feb 2014.

13. Andrew Robb BA, DC, CSCS ab Jason Pajaczkowski Bsc, BS, DC, FCCSS $(\mathrm{C})$, FCCRS(C), CSCS $^{\text {ac }}$. Immediate effect on pain threshold using active release technique on adductor strains: pilot study. Journal of Bodywork and Movement Therapies. January 2011. DOI.org/10.1016/j.jbmt.2010.04.004

14. Sajin Tak, Yongwoo Lee, Wonjae Choi, and Gyuchang Lee. The effect of active release technique on the gluteus medius for pain relief in person with chronic low back pain. Physical therapy rehabilitation science. July 2013. DOI: org/10.14474/ptrs.2013.2.1.27

15. Harneet K M, Khatri SM. Efficacy of Active Release Technique in Tennis Elbow - A Randomized Control Trial. Indian journal of physiotherapy and occupational therapy. July-September 2012.

How to cite this article: Shah JT, Ghumatkar M, Kumar A. Comparison between the immediate effect of instrument assisted soft tissue mobilization and active release technique in individuals wearing high heels. Int J Health Sci Res. 2021; 11(10): 186-195. DOI: https://doi. org/10.52403/ijhsr.20211024 